\title{
Efficient asymmetric addition of diethylzinc to ketones using tartaric acid derivative as chiral ligand
}

\author{
Ailing Hui, ${ }^{a}$ Jintang Zhang, ${ }^{b}$ Huayin Sun, ${ }^{\text {b }}$ and Zhiyong Wang ${ }^{b^{*}}$ \\ ${ }^{a}$ Engineering Research Center of Bio-process (Hefei University of Techonology), Ministry of \\ Education, 193 Tunxi Road, Hefei, Anhui 230009, PRC \\ ${ }^{b}$ Department of Chemistry, University of Science \& Technology of China, 96 Jinzhai Road, \\ Hefei, Anhui 230026, PRC \\ E-mail: zwang3@ustc.edu.cn
}

\begin{abstract}
A new chiral ligand derived from natural tartaric acid was synthesized and was applied to the asymmetric addition of diethylzinc to aldehyde and ketones. Moderate to good enantioselectivities were obtained in the asymmetric addition of diethylzinc to ketones with $10 \%$ mol catalyst loading at room temperature.
\end{abstract}

Keywords: Tartaric acid, asymmetric addition, diethylzinc, aldehyde, ketone

\section{Introduction}

Chiral alcohols are ubiquitous in the structure of natural products and drug compounds, and are also important precursors for many other functional organic molecules. One of the most useful methods for the asymmetric preparation of sec-alcohols and tert-alcohols is the enantioselective addition of dialkylzinc reagents to carbonyl compounds with chiral ligands ${ }^{1}$. Recent studies showed the ligands with $C_{2}$-symmetrical axes could catalyze dialkylzinc to aldehydes ${ }^{2}$ or ketones ${ }^{3}$. Taking the advantage of the chirality of L-tartaric acid, we ${ }^{4}$ designed and synthesized a series of ligands with $C_{2}$-symmetric axe, two of them were successfully applied to the asymmetric addition of diethylzinc to ketones. Recently, another new chiral ligands derived from L-tartaric acid were synthesized, as showed in Scheme 1. Furthermore, these ligands were employed as promoters in the addition of diethylzinc to aldehyde and ketones. 


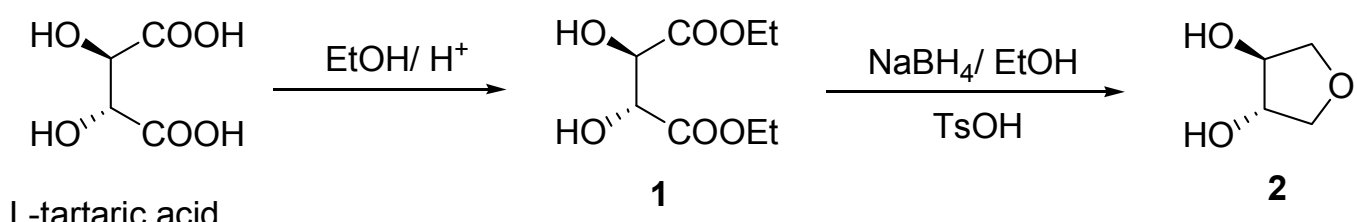

L-tartaric acid

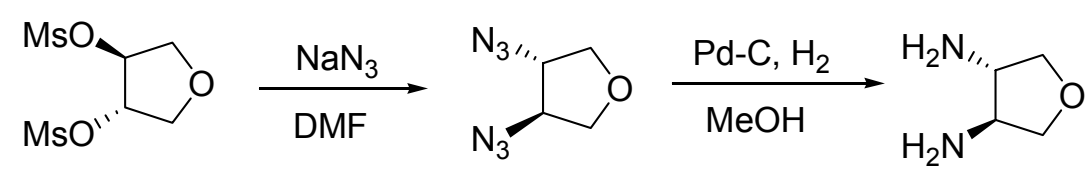

3

4

5<smiles>N[C@H]1COC[C@@H]1N[TeH]</smiles>

5

6

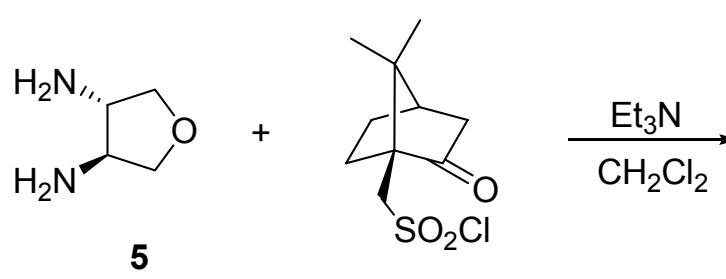<smiles></smiles>

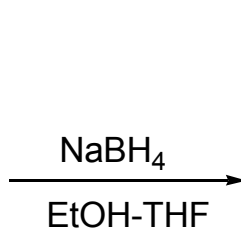<smiles>CC1(C)C2CCC(S(=O)(=O)NC3COCC3NS(=O)(=O)CC34CCC(CC3O)C4(C)C)(C(O)C2)C1O</smiles>

7

8

Scheme 1. Synthesis of the chiral ligands.

\section{Results and Discussion}

\section{Synthesis of the chiral ligands}

Initially, L-tartaric acid was easily transformed into its ester $\mathbf{1}$. Subsequently, 1 was reduced in the presence of sodium borohydride and closed ring with the aid of 4-methylbenzene sulfonic acid to obtain tetrahydrofuran 3, 4-diol 2. ${ }^{5}$ Then, the hydroxyl group in compound 2 was 
converted into amino group through three steps, which generated tetrahydro-3,4-diamine 5 with high yields. ${ }^{6}$ Once the diamine was available, it reacted with 4-methylbenzene-1-sulfonyl chloride and D-(+)-camphor sulfonyl chloride respectively and the chiral ligand $6{ }^{7}$ and $7^{2 \mathrm{e}}$ were synthesized. The carbonyl in the camphor ring of compound 7 was reduced and the diasteromer 8 was separated as a major product. ${ }^{3 \mathrm{a}}$

\section{Asymmetric addition of diethylzinc to aldehyde and ketones}

Our initial experiments in the asymmetric addition of diethylzinc to $p$-chlorobenzaldehyde involved the use of ligand 6, 7 and 8 (Scheme 2). Under the conditions the reaction was carried out smoothly, giving the desired secondary alcohol with high yields (entries 1-3 in Table 1). Among them ligand 6 gave the best enantioselectivity, which being up to 56\%ee (entry 1 in Table 1). So, we choosed the ligand $\mathbf{6}$ as the model catalyst for further trial. The modulation of the catalyst loading, the reaction solvent and the temperature were of no much improvement on the enantioselectivity (entries 4-8 in Table 1).

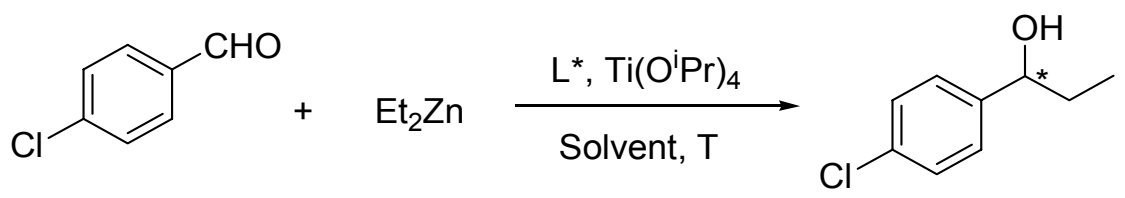

Scheme 2

Table 1. Optimization of the reaction conditions

\begin{tabular}{cccccc}
\hline Entry & $\mathrm{L}^{*}(\mathrm{~mol} \%)$ & Solvent & $\mathrm{T}\left({ }^{\circ} \mathrm{C}\right)$ & Yield $(\%)^{\mathrm{a}}$ Time $(\mathrm{h})$ & ee $(\%)^{\mathrm{b}}$ \\
\hline 1 & $\mathbf{6}(5)$ & Toluene & 20 & $90 / 2$ & 56 \\
2 & $7(5)$ & Toluene & 20 & $83 / 2$ & 27 \\
3 & $\mathbf{8}(5)$ & Toluene & 20 & $95 / 2$ & 44 \\
4 & $\mathbf{6}(10)$ & Toluene & 20 & $92 / 2$ & 57 \\
5 & $\mathbf{6}(10)$ & Hexane & 20 & $85 / 5$ & 48 \\
6 & $\mathbf{6}(10)$ & $\mathrm{Et}_{2} \mathrm{O}$ & 20 & $92 / 2$ & 50 \\
7 & $\mathbf{6}(10)$ & $\mathrm{CH}_{2} \mathrm{Cl}_{2}$ & 20 & $78 / 5$ & 43 \\
8 & $\mathbf{6}(10)$ & Toluene & 0 & $91 / 10$ & 54 \\
\hline
\end{tabular}

${ }^{a}$ isolated yields. ${ }^{b}$ The ee values were determined by chiral HPLC using Daicel OD-H column.

Afterwards, the chiral ligands were applied to the asymmetric addition of diethylzinc to $\mathrm{p}$ chloro acetophenone (Scheme 3). The results were listed in Table 2. As indicated the chiral ligand 8 gave the best enantioselectivity in high yields in toluene (entry 3 vs entries 1 or 2 in Table 2). Therefore, chiral ligand $\mathbf{8}$ was selected as the model catalyst for further optimization of the conditions. Using hexane as reaction solvent, the reaction only gave $52 \%$ yields with less than $50 \%$ ee (entry 4 in Table 2). It was ascribed to the weak solubility of $\mathbf{8}$ in hexane. The 
cooperation time of chiral ligand and titanium tetraisopropoxide was slightly propitious to the enantioselectivity. As illustrated in entry 5, the ee value was improved to $78 \%$ when the time was prolonged to 1 hour from 10 min (entry 5 vs entry 3 in Table 2). The further optimization in catalyst loading (entries 6-8 in Table 2), the temperature (entry 9 in Table 2) and the amount of $\mathrm{Et}_{2} \mathrm{Zn}$ (entry 10 in Table 2) established that the reaction condition in entry 6 were the optimal conditions for this type of asymmetric addition.
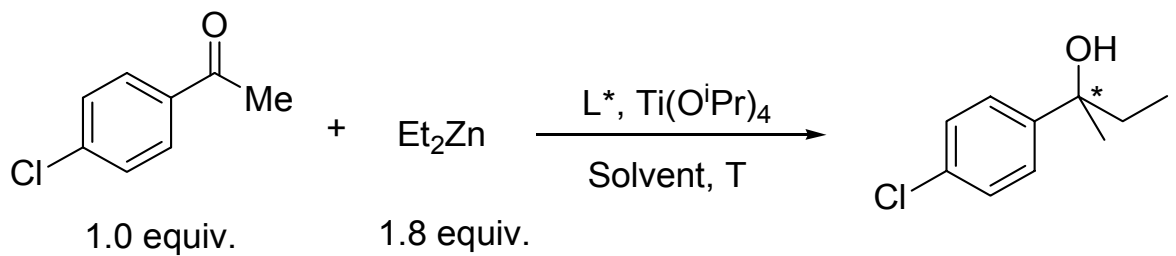

\section{Scheme 3}

Table 2. Enantioselective addition of diethylzinc to ketone under different conditions

\begin{tabular}{ccccccc}
\hline Entry & $\mathrm{L}^{*}(\mathrm{mmol} \%)$ & Solvent & $\mathrm{T}\left({ }^{\circ} \mathrm{C}\right)$ & Time $(\mathrm{h})$ & ${\text { Yield }(\%)^{\mathrm{a}}}^{\mathrm{c}}$ & Ee $(\%)^{\mathrm{b}}$ \\
\hline $1^{\mathrm{c}}$ & $\mathbf{6}(5)$ & toluene & 20 & 72 & - & - \\
2 & $\mathbf{7}(5)$ & toluene & 20 & 48 & 60 & 36 \\
3 & $\mathbf{8}(5)$ & toluene & 20 & 48 & 75 & 76 \\
4 & $\mathbf{8}(5)$ & hexane & 20 & 72 & 52 & 45 \\
$5^{\mathrm{d}}$ & $\mathbf{8}(5)$ & toluene & 20 & 48 & 76 & 78 \\
6 & $\mathbf{8}(10)$ & toluene & 20 & 50 & 77 & 80 \\
7 & $\mathbf{8}(15)$ & toluene & 20 & 50 & 76 & 80 \\
8 & $\mathbf{8}(7)$ & toluene & 20 & 50 & 75 & 79 \\
9 & $\mathbf{8}(10)$ & toluene & 0 & 60 & 68 & 78 \\
$10^{\mathrm{e}}$ & $\mathbf{8}(10)$ & toluene & 20 & 50 & 77 & 79 \\
\hline
\end{tabular}

${ }^{a}$ isolated yields. Unless other indicated, the chiral ligand and $\mathrm{Ti}\left(\mathrm{O}^{\mathrm{i}} \mathrm{Pr}\right)_{4}$ were mixed in the vessel and stirred for $10 \mathrm{~min}$ before other substrate was added into the system. ${ }^{\mathrm{b}}$ The ee values were determined by chiral HPLC using OJ-H column. ${ }^{\mathrm{c}}$ No desired product was detected. ${ }^{\mathrm{d}}$ The cooperation time was prolonged to 1 hour before other reagents were added to the vessel. The succedent experiment was performed according to this cooperation time. ${ }^{\mathrm{e}} 3$ equiv. $\mathrm{Et}_{2} \mathrm{Zn}$ was used in the reaction.

Having established the optimal conditions, different ketones were submitted to the addition in the presence of ligand $\mathbf{8}$ (Scheme 4). All the experimental results are illustrated in Table 3. As shown in Table 3, in all cases tested, acetophenone gave the best enantioselectivity, being up to 99\% with a good yield (entry 1 in Table 3). Electron-withdrawing substituents at the paraposition of acetophenone favored both enantioselectivity and reaction yield, with the enantiomeric excess ranged from $77 \%$ to $80 \%$ (entries $2-4$ in Table 3 ), while electron-donating 
substituents at the para-position of acetophenone disfavored either reaction yield or enantioselectivity (entries 6-8 in Table 3). The substituents at the ortho-position or meta-position of acetophenone were negative to the reaction. No desired products were detected when these substrates were introduced in the addition reaction (entries 5,9 and 10). These phenomena was ascribed to the steric repulsion of the substituent $(\mathrm{Cl}, \mathrm{Me})$ and the ethyl group. As a result, the ethyl nucleophile can hardly approach the carbon atom of carbonyl. In addition, we also investigated ketones containing heteroaromatic groups in the asymmetric addition, such as 2acetyl furan and 2-acetyl thiophene, which generated the corresponding products with low eanatioselectivities and moderate yields under the condition (entries 11 and 12 in Table 3). This result may stem from the binding of the heteroatom $(\mathrm{O}, \mathrm{S})$ in the substrate with the Ti center. Therefore, the reactivity and enantioselectivity of the chiral ligand were weakened to a certain extend. The same phenomenon was investigated in the addition of diethylzinc to 4-methoxy benzophenone (entry 6 in Table 3). It was noted that 2-acetyl naphthalene, which has more steic hindrance than other ketones, gave excellent enantioselectivity in this addition reaction (entry 13 in Table 3).

\section{Scheme 4}

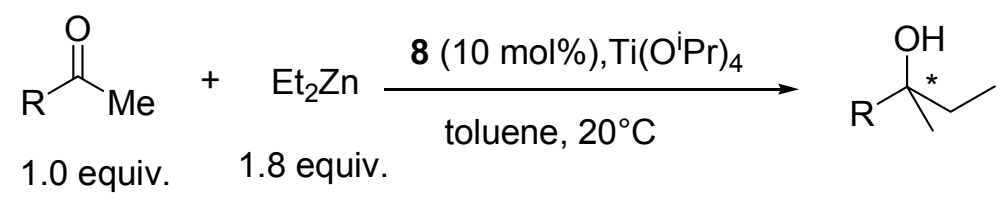

Table 3. Asymmetric addition of ethyl groups to ketones

\begin{tabular}{cccc}
\hline Entry & $\mathrm{R}$ & Yield (\%) $/$ Time(h) & ee (\%) \\
\hline 1 & $\mathrm{C}_{6} \mathrm{H}_{5}$ & $73 / 50$ & $99(\mathrm{~S})$ \\
2 & $4-\mathrm{FC}_{6} \mathrm{H}_{4}$ & $75 / 48$ & 80 \\
3 & $4-\mathrm{ClC}_{6} \mathrm{H}_{4}$ & $77 / 50$ & 80 \\
4 & $4-\mathrm{BrC}_{6} \mathrm{H}_{4}$ & $74 / 50$ & 77 \\
$5^{\mathrm{c}}$ & $2-\mathrm{ClC}_{6} \mathrm{H}_{4}$ & - & - \\
6 & $4-\mathrm{MeOC}_{6} \mathrm{H}_{4}$ & $67 / 60$ & 30 \\
7 & $4-\mathrm{MeC}_{6} \mathrm{H}_{4}$ & $58 / 60$ & 65 \\
8 & $4-\mathrm{PhC}_{6} \mathrm{H}_{4}$ & $78 / 48$ & 70 \\
$9^{\mathrm{c}}$ & $2-\mathrm{MeC}_{6} \mathrm{H}_{4}$ & - & - \\
$10^{\mathrm{c}}$ & $3-\mathrm{MeC}_{6} \mathrm{H}_{4}$ & - & - \\
$11^{\mathrm{d}}$ & $2-$ furan $_{12}$ & $68 / 60$ & 12 \\
$12^{\mathrm{d}}$ & $2-$ thiophene & $70 / 60$ & 15 \\
13 & 2-naphthyl & $79 / 48$ & 82 \\
\hline
\end{tabular}

${ }^{a}$ isolated yields. ${ }^{b}$ The ee values were determined by chiral HPLC using OD-H or OJ-H column.

${ }^{\mathrm{c}}$ No desired products were detected. ${ }^{\mathrm{d}} 2.5$ equiv. $\mathrm{Et}_{2} \mathrm{Zn}$ was used in the reaction. 


\section{Conclusions}

Three chiral ligands derived from natual tartaric acid were designed and synthesized. Among them, the chiral ligand $\mathbf{8}$ was optimized and applied to the asymmetric addition of diethylzinc to many ketones. Moderate to good enantioselectivities were obtained in this asymmetric addition reaction in the presence of titanium tetraisopropoxide. The reaction condition is mild and the catalyst loading is only $10 \mathrm{~mol} \%$. Further investigation on the scope of the reaction and the mechanism of the catalytic species is currently in progress.

\section{Experimental Section}

General Procedures. Unless other indicated, all reactions using diethylzinc and $\mathrm{Ti}\left(\mathrm{O}^{\mathrm{i}} \mathrm{Pr}\right)_{4}$ were carried out in dry glassware under nitrogen. Hexane, tetrahydrofuran, toluene and ether were freshly distilled from sodium and benzophenone. Dichloromethane was freshly distilled from $\mathrm{CaH}_{2}$. Titanium tetraisopropoxide was freshly distilled under reduced pressure. Triethylamine was distilled and stored in $4 \AA$ MS. Ethyl zinc solution was $1.5 \mathrm{M}$ in hexane and used directly. Reactions were monitored by thin-layer chromatography (TLC) analysis. ${ }^{1} \mathrm{H} N \mathrm{NR}$ and ${ }^{13} \mathrm{C}$ NMR were recorded on a Bruker AC-300 FT $\left({ }^{1} \mathrm{H}: 300 \mathrm{MHz},{ }^{13} \mathrm{C}: 75.5 \mathrm{MHz}\right)$ or AC-400 FT $\left({ }^{1} \mathrm{H}: 400\right.$ $\left.\mathrm{MHz},{ }^{13} \mathrm{C}: 100 \mathrm{MHz}\right)$ using TMS as internal reference. The chemical shifts $(\delta)$ and coupling constants $(J)$ were expressed in ppm and $\mathrm{Hz}$ respectively. IR spectra were recorded on a PerkinElmer 2000 FTIR. High resolution mass spectra were obtained on GCT-TOF spectrometer. The optical rotations were measured on WZZ-2 polarimeter. Chiral HPLC was performed in an Agilent 1100 series instrument equipped with a diode array detector. Chiralcel OD-H column and Chiralcel OJ-H column were purchased from Daicel chemical industries with $0.46 \mathrm{~cm} \Phi \times$ $25 \mathrm{~cm}$. Rention times for HPLC are given in min.

\section{Characterization of chiral ligands}

Compound 6. white solid, yield: $83 \%$; m.p. $=178-179^{\circ} \mathrm{C} ;[\alpha]_{\mathrm{D}}{ }^{28}=+58.8\left(c 0.2, \mathrm{CHCl}_{3}\right)$; IR (KBr) $3271(\mathrm{~m}), 1598(\mathrm{~m}), 1434(\mathrm{w}), 1321(\mathrm{~m}), 1155(\mathrm{~s}) \mathrm{cm}^{-1}$; ${ }^{1} \mathrm{H}$ NMR (300 MHz, $\left.\mathrm{CDCl}_{3}\right) 2.47$ $(6 \mathrm{H}, \mathrm{s}), 3.46-3.51(2 \mathrm{H}, \mathrm{m}), 3.69-3.72(2 \mathrm{H}, \mathrm{m}), 3.91-3.96(2 \mathrm{H}, \mathrm{m}), 5.10(2 \mathrm{H}, \mathrm{d}, J=4.2 \mathrm{~Hz}), 7.36$ $(4 \mathrm{H}, \mathrm{d}, J=7.8 \mathrm{~Hz}), 7.79(4 \mathrm{H}, \mathrm{d}, J=8.4 \mathrm{~Hz}) ;{ }^{13} \mathrm{C}$ NMR $(75.5 \mathrm{MHz}) 21.8(\mathrm{q}), 59.4(\mathrm{~d}), 71.6(\mathrm{t})$, 77.4 (t), 127.5 (d), 130.2 (d), 136.3 (s), 144.4 (s); Anal.calcd for $\mathrm{C}_{18} \mathrm{H}_{22} \mathrm{~N}_{2} \mathrm{O}_{5} \mathrm{~S}_{2}$ : C, 52.66; H, 5.40; N, 6.82. Found: C, 52.62; H, 5.39; N, 6.85 .

Compound 7. white solid granule, yield: $88 \%$; m.p. $=180-181^{\circ} \mathrm{C} ;[\alpha]_{\mathrm{D}}{ }^{28}=+44.0\left(\mathrm{c} 0.5, \mathrm{CHCl}_{3}\right)$; IR (KBr) 3248 (m), 2958 (m), 1745 (vs), 1336 (m), 1149 (m) cm ${ }^{-1}$; ${ }^{1} \mathrm{H}$ NMR (300 MHz, CDCl $)$ $0.94(6 \mathrm{H}, \mathrm{s}), 1.04(6 \mathrm{H}, \mathrm{s}), 1.47-1.51(2 \mathrm{H}, \mathrm{m}), 1.91-2.23(10 \mathrm{H}, \mathrm{m}), 2.37-2.45(2 \mathrm{H}, \mathrm{m}), 3.00(2 \mathrm{H}$, d, $J=15.3 \mathrm{~Hz}), 3.61(2 \mathrm{H}, \mathrm{d}, J=15.3 \mathrm{~Hz}), 3.78-3.82(2 \mathrm{H}, \mathrm{m}), 4.23-4.28(2 \mathrm{H}, \mathrm{m}), 5.54(2 \mathrm{H}, \mathrm{br})$; ${ }^{13} \mathrm{C}$ NMR (75.5 MHz) 19.7 (q), $20.0(\mathrm{q}), 26.4(\mathrm{t}), 27.1(\mathrm{t}), 42.3(\mathrm{~d}), 48.7$ (s), $50.5(\mathrm{t}), 58.3(\mathrm{~d})$, 
$59.1(\mathrm{t}), 59.8(\mathrm{~s}), 72.3(\mathrm{t}), 216.1$ (s); Anal. Calcd for $\mathrm{C}_{24} \mathrm{H}_{38} \mathrm{~N}_{2} \mathrm{O}_{7} \mathrm{~S}_{2}:$ C, 54.32; H, 7.22; N 5.28. Found: C, 54.30; H, 7.19; N 5.30.

Compound 8. White solid, yield: $36 \%$; m.p. $=193-195^{\circ} \mathrm{C} ;[\alpha]_{\mathrm{D}}{ }^{28}=-30.0\left(c 0.5, \mathrm{CHCl}_{3}\right)$; IR (KBr) 3526 (m), 3277 (m), 2955 (m), 1455 (w), 1320 (m), 1144 (s) cm ${ }^{-1}$; ${ }^{1} \mathrm{H}$ NMR (400 MHz, $\left.\mathrm{CDCl}_{3}\right) 0.85(6 \mathrm{H}, \mathrm{s}), 1.07(6 \mathrm{H}, \mathrm{s}), 1.13-1.15(1 \mathrm{H}, \mathrm{m}), 1.23-1.28(1 \mathrm{H}, \mathrm{m}), 1.45-1.51(2 \mathrm{H}, \mathrm{m})$, 1.70-1.81 (10H, m) $2.55(2 \mathrm{H}, \mathrm{br}), 2.99(2 \mathrm{H}, \mathrm{d}, J=13.8 \mathrm{~Hz}) ; 3.56(2 \mathrm{H}, \mathrm{d}, J=13.8 \mathrm{~Hz}), 3.66-3.70$ $(2 \mathrm{H}, \mathrm{m}), 4.03-4.13(4 \mathrm{H}, \mathrm{m}), 4.14-4.20(4 \mathrm{H}, \mathrm{m}), 5.13(2 \mathrm{H}, \mathrm{br}) ;{ }^{13} \mathrm{C} \mathrm{NMR}(100 \mathrm{MHz}) 20.0$ (q), $20.6(\mathrm{q}), 27.4(\mathrm{t}), 30.5(\mathrm{t}), 39.5(\mathrm{t}), 44.5(\mathrm{~d}), 49.0(\mathrm{~s}), 50.6(\mathrm{~d}), 53.3(\mathrm{~s}), 59.8(\mathrm{t}), 71.8(\mathrm{t}), 76.5(\mathrm{~d})$; $\mathrm{m} / \mathrm{z}$ (HPLC-ESI/MS) $533(\mathrm{M}-\mathrm{H})^{-}$; Anal. Calcd for $\mathrm{C}_{24} \mathrm{H}_{42} \mathrm{~N}_{2} \mathrm{O}_{7} \mathrm{~S}_{2}$ : C, 53.91; H, 7.92; N 5.24. Found: C, 53.81; H, 7.98; N 5.30.

General procedure for enantioselective addition of diethylzinc to $p$-chlorobenzaldehyde (6) (10 mg, $0.025 \mathrm{mmol}, 0.05$ equiv.) and $\mathrm{Ti}\left(\mathrm{O}^{\mathrm{i}} \mathrm{Pr}\right)_{4}(175 \mathrm{mg}, 0.6 \mathrm{mmol}, 1.2$ equiv.) were dissolved in toluene $(2 \mathrm{ml})$ or other solvents under nitrogen. The resulting mixture was stirred for $10 \mathrm{~min}$. Diethylzinc solution $0.6 \mathrm{ml}$ (1.8 equiv., $1.5 \mathrm{M}$ in hexane) was added to above vessel. 2 minutes later, p-chlorobenzaldehyde $70 \mathrm{mg}(0.5 \mathrm{mmol}, 1.0$ equiv., dissolved in $0.5 \mathrm{ml}$ toluene or other solvents) were added at this temperature. The reaction was stirred for the appointed time in Table 1 until it was quenched with diluted hydrochloric acid. The resulting mixture was filtered through silica gel, extracted with ethyl acetate $(3 \times 10 \mathrm{ml})$ and the organic layer dried over anhydrous $\mathrm{Na}_{2} \mathrm{SO}_{4}$. The solvent was removed under reduced pressure and the residue was purified by flash chromatography column to afford the expected sec-alcohol. The enantiomeric excess was determined by chiral HPLC.

\section{General procedure for enantioselective addition of diethylzinc to ketones}

Ligand 8 (27 mg, $0.05 \mathrm{mmol}, 0.1$ equiv.) and $\mathrm{Ti}\left(\mathrm{O}^{\mathrm{i}} \mathrm{Pr}\right)_{4}$ (175 mg, $0.6 \mathrm{mmol}, 1.2$ equiv.) were dissolved in toluene $(2.5 \mathrm{ml})$ under nitrogen. The resulting mixture was stirred for 1 hour at room temperature $\left(20^{\circ} \mathrm{C}\right)$. Diethylzinc solution $(0.6 \mathrm{ml}, 0.9 \mathrm{mmol}, 1.5 \mathrm{M}$ in hexane $)$ was added to above flask and the color of solution became orange-green. After $2 \mathrm{~min}$, the corresponding ketone $(0.5 \mathrm{mmol}, 1.0$ equiv., dissolved in $0.5 \mathrm{ml}$ toluene or diluted with $0.5 \mathrm{ml}$ toluene) was added at this temperature. The reaction was stirred for the appointed time in the Table 3 until it was quenched with diluted hydrochloric acid. The following work up was the same with above procedure.

All the spectral data of tert-alcohol and 1-(p-chlorophenyl)-1-propanol were listed in the previous paper ${ }^{4 a}$.

\section{Acknowledgements}

The authors are grateful to National Natural Science Foundation of China (No.20472078 and 30572234) for finacial support. 


\section{References}

1. (a) Pu, L.; Yu, H. B. Chem. Rev. 2001, 101, 757. (b) Pu, L. Tetrahedron 2003, 59, 9873. (c) Ramón, D. J.; Yus, M. Angew. Chem., Int. Ed. 2004, 43, 284. (d) Betancort, J. M.; García, C.; Walsh, P. J. Synlett 2004, 749.

2. (a) Yoshioka, M.; Kawakita, T.; Ohno, M. Tetrahedron Lett. 1989, 30, 1657. (b) Takahashi, H.; Kawakita, T.; Yoshioka, M.; Kobayashi, S.; Ohno, M. Tetrahedron Lett. 1989, $30,7095$. (c) Takahashi, H.; Kawakita, T.; Ohno, M.; Yoshioka, M.; Kobayashi, S. Tetrahedron 1992, 48, 5691. (d) Pritchett, S.; Woodmansee, D. H.; Walsh, P. J. J. Am. Chem. Soc. 1998, 120, 6423. (e) Balsells, J.; Walsh, P. J. J. Am. Chem. Soc. 2000, 122, 3250. (f) Balsells, J.; Betancort, J. M.; Walsh, P. J. Angew. Chem., Int. Ed. 2000, 39, 3428. (g) Zhang, X. M.; Guo, C. Tetrahedron Lett. 1995, 36, 4947. (h) Qiu, J.; Guo, C.; Zhang. X. M. J. Org. Chem. 1997, 62, 2665.

3. (a) García, C.; LaRochelle, L. K.; Walsh, P. J. J. Am. Chem. Soc. 2002, 124, 10970. (b) Yus, M.; Ramón, D. J.; Prieto, O. Tetrahedron: Asymmetry 2002, 13, 2291. (c) Yus, M.; Ramón, D. J.; Prieto, O. Eur. J. Org. Chem. 2003, 2745. (d) García, C.; Walsh, P. J. Org. Lett. 2003, 5, 3641. (e) Prieto, O.; Ramón, D. J.; Yus, M. Tetrahedron: Asymmetry 2003, 14, 1955. (f) Yus, M.; Ramón, D. J.; Prieto, O. Tetrahedron: Asymmetry 2003, 14, 1103. (g) de Parrodi, C. A.; Walsh, P. J. Synlett 2004, 2417. (h) Forrat, V. J.; Ramón, D. J.; Yus, M. Tetrahedron: Asymmetry 2005, 16, 3341. (i) Jeon, S. J.; Li, H. M.; García, C.; LaRochelle, L. K.; Walsh, P. J. J. Org. Chem. 2005, 70, 448. (j) Jeon, S. J.; Li, H. M.; Walsh, P. J. J. Am. Chem. Soc. 2005, 127, 16416.

4. (a) Hui, A. L.; Zhang, J. T.; Fan, J. M.; Wang, Z. Y. Tetrahedron: Asymmetry 2006, 17, 2101. (b) Hui, A. L.; Zhang, J. T.; Wang, Z. Y. Synth. Commun. 2007, accepted.

5. Terfort, A. Synthesis 1992, 951.

6. (a) Kuppert, D.; Sander, J.; Roth, C.; Worle, M.; Weyhermuller, T.; Reiss, G. J.; Schilde, U.; Muller, I.; Hegetschweiler, K. Eur. J. Inorg. Chem. 2001, 2525. (b) Slarżewski, J.; Gupta, A. Tetrahedron: Asymmetry 1997, 8, 1861.

7. You, J. S.; Shao, M. Y.; Gau, H. M. Tetrahedron: Asymmetry 2001, 12, 2971. 